\title{
What is cognitive science?
}

\section{By Julia Lee Ai Cheng}

AS a lecturer who works at the Faculty of Cognitive Sciences and Human Development, friends or acquaintances frequently ask me what cognitive science means.

\section{History}

Cognitive science is a very young science in the world and even more cognitive science dates back to the time of the Greek philosophers such is Socrates and Plato when they as Socrates and Plato when they
began ruminating about the human intellect. They were possessed by the quest to answer questions such as: Where is the mind? What does it consist of? How is knowledg represented in the human mind? However, the questions of the human intellect were put aside when scholars such as Ivan Pavlov, B F Skinner, and J B Watson, who subscribed only to the public
methods of observing the human mind and to the science of behaviour, toppled the proponents who were interested in understanding the human mind. These three scholars, known as behaviourists, were more interested in explaining how the human being functions from observable behaviours.

After much debate in the 1940s the "forefathers" of cognitivescience began to realise that a better and more scientific study of the mind was on its way. They were convinced that human activities such as learning, speaking, and performing on a musical instrument can be accounted for with insights about the brain and computers

In the mid-1950s researchers from various areas such as linguistics, mathematics, neurophysiology, computer science, and artificial intelligence met at the Massachusetts Institute of Technology for a symposium on information science (Gardner, 1985). They wanted to understand the functions of the mind and began to build theories of the mind using complex computational representations with the help of to the cognitive revolution and conitive science was born.

The researchers' quest to understand the mind led to the idea that there were similarities between the computer and the human mind. The computer was a useful analogy
to understand the human mind.

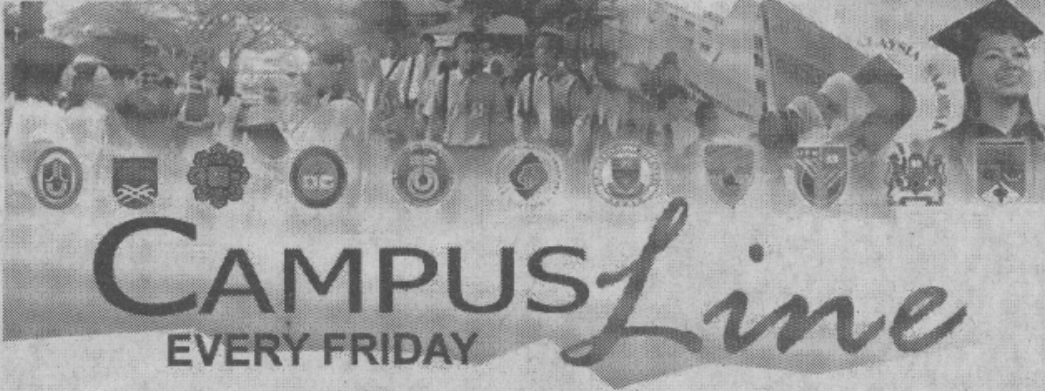

Computers have input facilities such as the keyboard, mouse, bar code reader, and joy stick, while human beings have five senses to receive and filter information.

Computers have hard disks which are very similar to the long-term memory in human beings. Computers also have software programmes to run a set of procedures while human beings have memories in the mind capable of remembering procedures and knowledge to function efficiently and effectively in the world.

Computers have output tools such as the computer monitor and printed hardcopies while human beings have the capability of producing knowledge representations of the world around them.

Based on this discovery, the early cognitive scientists began to rely heavily on computers to understand how the human mind functions. This knowledge of the similaritie between the human mind and computer systems was thought be able to guide research in both psychology and computer science. The computer serves as the mos viable model of how the human mind works.

What is cognitive science?

Today, cognitive science refers to the scientific study of the mind; how we think, perceive, remember, and learn. The coalition of researchers from various fields such as philosophy, psychology, artificial intelligence, neuroscience, inguistics, education, and anthropology has resulted in the interdisciplinary study of the mind through the studies and exchange of ideas of researchers in these fields.

As the human mind is the focus of the field, what was previously studied in a compartmentalised manner has now amalgamated to form clearer understandings of the human mind. The MIT Encyclopaedia of the Cognitive Sciences classifies the cognitive such as singing, reading, crying, and sleeping.

Today, there are many noninvasive machines in the market that can scan the brains of both adults and children.

The popular types of brain scanners are Magnetic Resonance Imaging (MRI) and Functional Magnetic Resonance Imaging (fMRI). The use of these machines has illuminated complex problems such as dyslexia.

Researchers-cum-Professors of Paediatrics such as Sally Shaywitz and Bennett Shaywitz from Yale University have found through the University have found through the
use of the fMRI that they could use of the fMRI that they could directly evaluate the effects of neural systems for reading (Yale Bulletin, 2004)

With the use of these high-tech tools they were able to discover that early intervention and effective reading instructions are important to take advantage of the plasticity of our human brain. This finding is very important because it points us to the path where education and health sciences experts can come together, exchange ideas, and discover a holistic solution to address dyslexia in society.

The field of cognitive science is therefore extremely important for
theadvancement of society, whether we are solving social problems or specific problems such as the learning disorder just mentioned. Applications

The applications of cognitive cience research are vast. Today basic cognitive science research has also moved into the classroom. A science of learning is possible because of the many research projects undertaken on cognitive development to understand how children learn. Going deep enough using what we know about cognitive science such as how the human mind works is helping us improve teaching and learning.

Zawawi Ismail (1998) mentioned in his keynote address on the Business of the Mind at the National Conference on Cognitive Science in 1998 that the understanding of cognitive science will also be able to address issues of human resource development and the management of organisations.

Recently, I learned from a professor from Nanyang Technological University of
Campus Line invites academicians from university and college campuses in Sarawak to submit articles on their work, their areas of research, anecdotes or even creative writing for. publication. All contributions should be in Microsoft Word, Times New Roman, 12 points over 1.5 lines spacing and between 750 and 1200 words and sent to The Editor, Campus Line at campusline@gmail.com. The Borneo Post

reserves the right to accept, reject or appropriately edit contributions which are not returnable. Singapore that we can apply the
"Language of Leadership" to frame the minds of our subordinates. She suggested that "Language is the most powerful tool of influence. As leader we must be selective of the image that we want to create or frame in the minds of people around us. Messages that are not thought of carefully or crafted well are much less likely to have the impact we want:" Therefore, from my perspective, the understanding of how people understand messages is useful for those leaders who are interested to embark on paths of transformational leadership.

As you can see by now, the areas of application in cognitive science ar so vast. It only depends on how faculty in a university defines it niche areas. Cognitive science has a lot to contribute to ou understanding of human development. The problems we face today are human development issues and they have to be analysed from a cognitive perspective.

For example, rapists should not only be jailed. Their minds and thinking processes should be investigated. Questions I raised about the recent case in Thailand and Sungai Petani are: Why did they want to rape and kill a woman without any alibi only to be jailed hours later after a short session of brutal fun?

Understanding the minds of criminals and killers would help us understand more about these socia threats and would help us think further about preventive measures. We certainly do not want to build more jail cells. We want society to progress and not regress.

Cognitive science in Malaysia

Internet research reveals that there are more than 60 universitie worldwide that offer Cognitiv Science as a field of study. This lis includes universities such as the University of California-Berkeley,

University of Edinburgh, Johns Hopkins University, University of Illinois at Urbana-Champaign, and Technology.

Universiti Malaysia Sarawak one of the three universities in Malaysia having trailblazed this new field through the setting p of a faculty that offers cognitive science courses to its students.

The vision for the establishment of the Faculty of Cognitive Sciences in the Unimas Tree Book (1993).

The pioneer leader of the university at that time mentioned that "as our society becomes more knowledge-based, ever more skills are required. New approaches will need to be sought to solve issues of growing complexity, and one central aspect of such change is the mind itself."

It was visualised that the Faculty of Cognitive Sciences and Human Development would "be geared towards the issues of creativity, echnology utilisation, and value reinforcement.

To conclude, I share one last question people have asked me about ognitive science. Can people, rained in cognitive science or 